\title{
2021 European Thyroid Association Guideline on Thyroid Disorders prior to and during Assisted Reproduction
}

\author{
Kris Poppe $^{\mathrm{a}}$ Peter Bisschop $^{\mathrm{b}}$ Laura Fugazzola ${ }^{\mathrm{c}}$ Gesthimani Minziori ${ }^{\mathrm{d}}$ \\ David Unuane $^{e}$ Andrea Weghofer $^{f}$ \\ aEndocrine Unit, CHU Saint-Pierre, Université Libre de Bruxelles (ULB), Brussels, Belgium; 'b Department of \\ Endocrinology, Amsterdam UMC, University of Amsterdam, Amsterdam, The Netherlands; 'Division of \\ Endocrine and Metabolic Diseases, IRCCS Istituto Auxologico Italiano, and Department of Pathophysiology \\ and Transplantation, University of Milan, Milan, Italy; dUnit of Reproductive Endocrinology, First Department of \\ Obstetrics and Gynaecology, Medical School, Aristotle University of Thessaloniki, Thessaloniki, Greece; eDepartment \\ of Internal Medicine, Endocrine Unit, UZ Brussel, Vrije Universiteit Brussel (VUB), Brussels, Belgium; ${ }^{\text {DDepartment of }}$ \\ Gynecological Endocrinology \& Reproductive Medicine, Medical University of Vienna, Vienna, Austria
}

\section{Keywords}

Subfertility · Assisted reproductive technology $\cdot$ In vitro fertilization · Intracytoplasmic sperm injection . Thyroid autoimmunity · Subclinical hypothyroidism/ hyperthyroidism - Thyroid cancer · Radioactive iodine

\begin{abstract}
Severe thyroid dysfunction may lead to menstrual disorders and subfertility. Fertility problems may persist even after restoring normal thyroid function, and then an assisted reproductive technology (ART) may be a solution. Prior to an ART treatment, ovarian stimulation is performed, leading to high oestradiol levels, which may lead to hypothyroidism in women with thyroid autoimmunity (TAl), necessitating levothyroxine (LT4) supplements before pregnancy. Moreover, women with the polycystic ovarian syndrome and idiopathic subfertility have a higher prevalence of TAI. Women with hypothyroidism treated with LT4 prior to ART should have a serum TSH level $<2.5 \mathrm{mIU} / \mathrm{L}$. Subfertile women with hyperthyroidism planning an ART procedure should be informed of the increased risk of maternal and foetal complications,
\end{abstract}

karger@karger.com www.karger.com/etj

(c) 2021 European Thyroid Association Published by S. Karger AG, Basel and euthyroidism should be restored and maintained for several months prior to an ART treatment. Fertilisation rates and embryo quality may be impaired in women with TSH $>4.0 \mathrm{mIU} / \mathrm{L}$ and improved with LT4 therapy. In meta-analyses that mainly included women with TSH levels $>4.0 \mathrm{mIU} / \mathrm{L}$, LT4 treatment increased live birth rates, but that was not the case in 2 recent interventional studies in euthyroid women with TAl. The importance of the increased use of intracytoplasmic sperm injection as a type of ART on pregnancy outcomes in women with TAl deserves more investigation. For all of the above reasons, women of subfertile couples should be screened routinely for the presence of thyroid disorders.

(c) 2021 European Thyroid Association Published by S. Karger AG, Basel

\section{Introduction}

The prevalence of thyroid disorders in women aged $20-45$ years is high, and that of subfertility is increasing worldwide in part due to improved public awareness and diagnosis. Therefore, the female partner in a subfertile 
couple carries a high risk of concomitant thyroid disorders. The prevalence of thyroid disorders in this group of women has been estimated to be between 5 and $7 \%$ for subclinical hypothyroidism (SCH), 2-4.5\% for overt hypothyroidism $(\mathrm{OH}), 0.5-1 \%$ for hyperthyroidism, and $5-10 \%$ for thyroid autoimmunity (TAI) [1]. Subfertility is estimated to affect between 8 and 12\% of reproductiveaged couples worldwide. Males are found to be solely responsible for $20-30 \%$ of subfertility cases but contribute to $50 \%$ of cases overall [2]. In $2005,56 \%$ of assisted reproductive technology (ART) cycles were performed in Europe, $23 \%$ in Asia, and 15\% in North America; furthermore, worldwide, the use of ART is increasing over the years [3].

Given the important interplay between thyroid hormone $(\mathrm{TH})$ and its receptor present on reproductive organs, thyroid dysfunction may be directly causative for menstrual disturbances and subfertility. Moreover, thyroid dysfunction may act indirectly by altering the secretion of gonadotropin-releasing hormone $(\mathrm{GnRH})$ and other hormones like prolactin $[4,5]$. Although restoring thyroid function can normalize the menstrual pattern and/or the reproductive hormonal profile, it is not always followed by pregnancy. In case of male subfertility, endometriosis or tubal obstruction, surgery, and/or an ART procedure may be necessary.

TAI is the major cause of (subclinical) hypothyroidism in Europe and is more prevalent in women with idiopathic subfertility and polycystic ovarian syndrome (PCOS) than in fertile women $[6,7]$. The prevalence of TAI is also higher in women with diminished ovarian reserve (DOR) and premature ovarian insufficiency $[8,9]$. Furthermore, serum TSH levels are inversely correlated with the antiMüllerian hormone, an accurate marker of the ovarian reserve [9].

Before the in vitro phase of the ART procedure, ovarian stimulation (OS) is performed, aiming to collect as many oocytes as possible. OS leads to an increase in oestradiol levels and consequently thyroxine-binding globulin (TBG) levels, and that increased demand on the thyroid gland can lead to (subclinical) hypothyroidism in women with TAI. Women already treated with levothyroxine (LT4) should adapt the dose of LT4 at least 4 weeks before OS. Women with (subclinical) hypothyroidism should initiate LT4 to keep serum TSH levels $<2.5 \mathrm{mIU} / \mathrm{L}$ [10].

Concerning the in vitro outcomes of an ART procedure, the number of oocytes retrieved (NOR) is not influenced by TAI or thyroid function. Hence, here, LT4 is of no benefit to increase the oocyte retrieval rate. It is impor- tant to notice that age ( $>30$ years) is the strongest predictor of a low oocyte retrieval rate $[11,12]$. Fertilization rates and embryo quality might be impaired in women with TSH levels $>4.0 \mathrm{mIU} / \mathrm{L}$ and may be improved with LT4 treatment $[11,13]$.

The impact of thyroid dysfunction before ART on the live birth rate (LBR) seems to emerge at TSH levels $>3.5$ $\mathrm{mIU} / \mathrm{L}$ and upwards [14]. In a meta-analysis mainly including women with TSH levels $>4.0 \mathrm{mIU} / \mathrm{L}$, LT4 treatment increased LBR to comparable rates to those in women without elevated TSH [11].

In a recent meta-analysis investigating the impact of euthyroid TAI on ART pregnancy outcomes, no decreased LBR was observed [15]. This discrepancy with previous meta-analysis concluding a detrimental impact of TAI could be due to the inclusion of women with lower TSH levels $(<3.0 \mathrm{mIU} / \mathrm{L})$ and the use of ICSI as the main type of ART $[16,17]$. Noteworthy, therefore, is that in a recent interventional study with LT4 in euthyroid subfertile women with TAI, LT4 did not increase LBR [18].

For all the above-mentioned reasons, women of subfertile couples should be screened systematically for serum TSH and TAI before an ART procedure. Women with serum TSH $>4.0 \mathrm{mIU} / \mathrm{L}$ and $\mathrm{OH}$ should be treated with LT4 independently of the presence of TAI. In women with TSH levels $>2.5 \mathrm{mIU} / \mathrm{L}$ and TAI, treatment with LT4 could be initiated in a case-by-case manner taking into account among other causes of female subfertility and a history of previous (failed) ART treatments.

\section{Methodology/Definitions}

The development of this guideline was commissioned by the Executive Committee (EC) and the Guidelines and Publication Board of the European Thyroid Association (ETA), which selected a chairperson (K.P.) to lead the task force. Subsequently, and after agreement of the ETA EC, K.P. assembled a team of European clinicians who authored this manuscript. Membership on the panel was based on clinical expertise, scholarly approach, representation of endocrinology, and mostly are ETA members. The task force examined the relevant literature using a systematic PubMed search supplemented with additional published materials. An evidence-based medicine approach that incorporated the knowledge and experience of the panel was used to develop the text and a series of specific recommendations. The strength of the recommendations and the quality of evidence supporting each 
were rated according to the approach recommended by the Grading of Recommendations, Assessment, Development, and Evaluation (GRADE) system [19]. The ETA task force for this guideline used the following coding system: (a) strong recommendation indicated by 1 and (b) weak recommendation or suggestion indicated by 2 . Evidence grading: ØООО denotes very low-quality evidence; $\varnothing \varnothing О О$, low quality; $\varnothing \varnothing \varnothing О$, moderate quality; and $\varnothing \varnothing \varnothing \varnothing$, high quality. The draft was discussed by the task force and then posted on the ETA website for 4 weeks for critical evaluation by the ETA members. After each chapter, we provide chapter-specific recommendations/ suggestions, and the most important ones for the whole guideline are summarized in a separate table. The target audiences for this guideline are endocrinologists and gynaecologists providing care to subfertile couples with thyroid disorders.

$\mathrm{SCH}$ is the association of a normal free thyroxine level (FT4) and an increased serum TSH level above the upper limit of normality. Ideally, this upper limit is determined in an assay and population-specific cohort and in the scope of (sub)fertility in women in the age range 20 45 years. Most centres do not have these normative data, and therefore the upper limit of normality is most often synonym for the upper limit of the reference range (ULRR) of the assay used. The most commonly used commercial assays in Europe have an ULRR for serum TSH between 3.60 and $4.31 \mathrm{mIU} / \mathrm{L}$ [20]. In a recent metaanalysis, altered ART outcomes were present from TSH levels of $3.5 \mathrm{mIU} / \mathrm{L}$ and upwards, but in 2 interventional trials with LT4, an increased LBR was present only when TSH levels exceeded 4.0 and $4.5 \mathrm{mIU} / \mathrm{L}$, respectively [13, $14,21]$. Based on these factors, therefore, we propose to define SCH (and to initiate treatment with LT4) from a TSH cutoff $>4.0 \mathrm{mIU} / \mathrm{L}$ or $>$ ULRR if the latter is $>4.0$ $\mathrm{mIU} / \mathrm{L}$. If these conditions are not fulfilled, and serum TSH is not suppressed/low, women are considered being euthyroid.

The term "TAI" is used in many recommendations/ suggestions and throughout the document when at least one type of thyroid $\mathrm{Ab}$ was increased according to the manufacturer's threshold. In the majority of the studies, thyroid peroxidase antibodies (TPOAb) were measured, but sometimes thyroglobulin antibodies (TgAb) or both types were measured. In exceptional cases, sonographic features of autoimmunity were provided. If there is a particular chapter/topic where only one Ab was measured or associated with the respective outcome investigated, it is mentioned explicitly.

Management of Thyroid Disorders and Assisted Reproduction

\section{Discussion}

\section{Thyroid Disorders and Female Subfertility}

In women of reproductive age, both thyroid dysfunction and TAI are prevalent and have separately been associated with various reproductive difficulties $[4,22]$. Given this connection, however, establishing causation remains daunting to date. Various mechanisms for the relationship between thyroid disorders and subfertility have been suggested. Indeed, TH appears to play an important role in the regulation of ovarian function, and consequently thyroid dysfunction may lead to menstrual and ovulatory disturbances $[4,23]$.

Subfertility is a disease of the reproductive system defined by the failure to achieve a clinical pregnancy after 12 months or more of regular unprotected sexual intercourse [24]. Female-related subfertility accounts for 35\%, male factors for $30 \%$, and combined male and female factors for $20 \%$ of the causes of subfertility. In $15 \%$ of the cases, the cause remains unknown [4].

Thyroid Dysfunction and Female Subfertility

Subclinical and Overt Hypothyroidism and Female

Subfertility

Hypothyroidism prevalence varies from 2 to $4 \%$ and is largely attributed to TAI. SCH is more prevalent amounting for as high as $10 \%$ in women of fertile age $[1,22]$.

In $\mathrm{OH}$, a number of different hormonal changes can be noted. Altered metabolic clearance, increased peripheral aromatisation, and decreased sex hormone binding globulin (SHBG) result in decreased total serum testosterone and oestradiol (E2) concentrations whilst their unbound fraction increases. In addition, prolactin levels tend to increase, which may impair pulsatile secretion of GnRH. Subsequently, this can lead to ovulatory dysfunction and an insufficient corpus luteum with low progesterone production. Indeed, menstrual aberrations are reported in $25-60 \%$ of the cases compared to $10 \%$ in euthyroid women [4]. Overall, data suggest that $\mathrm{OH}$ is associated with an increased risk of adverse effects on fertility as well as early and late complications of pregnancy [6]. If treated with LT4, hormonal changes are usually reversed, restoring a normal menstrual pattern and potentially improving fertility [4].

Whether the prevalence of $\mathrm{SCH}$ is higher in subfertile women remains uncertain. Similarly, any detrimental impact of $\mathrm{SCH}$ on fertility is yet to be established. Different cutoffs used to define the upper limit of normal TSH concentration and a lack of well-designed prospective studies have led to contradictory conclusions [4, 25-27]. How- 
ever, based on these studies, association with adverse fertility outcomes seems to surface at TSH levels $>4.0 \mathrm{mIU} / \mathrm{L}$ [26]. To date, there are no randomized controlled trials (RCTs) evaluating the benefit of LT4 on spontaneous pregnancy rates in women with SCH/TAI. Among subfertile women with TAI, a meta-analysis of 3 RCTs, including 2 studies that used TSH levels $>4.0 \mathrm{mIU} / \mathrm{L}$ to define $\mathrm{SCH}$, found a beneficial effect of LT4 on pregnancy after ART [11].

Subclinical and Overt Hyperthyroidism and Female Subfertility

Because of limited data in the literature, the degree to which hyperthyroidism is linked to fertility issues is not well known. Nevertheless, increased levels of SHBG and E2 have been reported in patients with thyrotoxicosis compared to euthyroid women. In addition, in patients with Graves' disease, LH secretion is increased compared to euthyroid patients. Menstrual irregularities have been identified in up to $65 \%$ of hyperthyroid women compared to $17 \%$ in healthy controls [4]. Recent reports have shown a lower incidence of menstrual anomalies of around 22\% compared to $8 \%$ in healthy controls. However, hyperthyroidism is generally associated with early pregnancy loss if not treated appropriately [4].

\section{TAI in Women with Female Subfertility}

TAI is the most common autoimmune disorder in women in the reproductive age range. The prevalence of TAI can vary by ethnic background but is typically estimated at around 10\% [22]. Overall, TAI is characterized by increased levels of TPOAb and associated with high(er) TSH concentrations [22]. Although a higher prevalence of elevated $\operatorname{TgAb}$ levels has been reported in women with subfertility, their significance remains uncertain [28]. Research examining TAI prevalence in subfertile women or any association between TAI and fertility outcomes is therefore largely based on the presence of increased $\mathrm{TPOAb}$ levels alone.

TAI tends to be more prevalent in women confronted with subfertility. A meta-analysis pooling 4 studies found that thyroid antibodies are associated with unexplained subfertility in euthyroid patients (OR 1.5, 95\% CI: 1.12.0) [6]. Nonetheless, the mechanism connecting TAI and idiopathic subfertility remains speculative. On the one hand, a TH-dependent effect may occur as the risk of (subclinical) hypothyroidism in women with TAI is increased, especially during pregnancy [4]. However, there seems to be no benefit of LT4 treatment before conception on pregnancy outcomes in euthyroid women with
TAI facing subfertility or recurrent miscarriage $[18,29]$. On the other hand, it has also been speculated that the presence of TAI reflects a general immune imbalance that could lead to failure of implantation, and in a recent study, it was shown that TPO is expressed at gene and protein levels in the endometrium and placenta and may explain the higher frequency of miscarriage and infertility in patients with TAI [30]. Furthermore, another specific cause of subfertility, PCOS, has been associated with TAI $[7,25]$. In the case of PCOS, a plausible explanation could be that polymorphisms of the PCOS-related gene for fibrillin-3 alter the activity of TGF- $\beta$, a regulator of immune tolerance. In combination with a high oestrogen-to-progesterone ratio, this may contribute to autoimmunity [7].

\section{Chapter-Specific Recommendations/Suggestions}

We recommend that all women seeking medical advice for subfertility should be screened for serum TSH and TPOAb. TgAb can be added systematically according to the local regulatory authority rules $(1, \varnothing \varnothing \varnothing O)$. We suggest that subfertile women with TSH levels $>2.5 \mathrm{mIU} / \mathrm{L}$ and without increased TPOAb levels (according to the local reference range) should be screened for the presence of increased $\mathrm{TgAb}$ levels if not yet done at initial workup (2, ØØОO). We recommend LT4 treatment should be started promptly in case of overt thyroid dysfunction (1, $\varnothing \varnothing \varnothing \mathrm{O})$. We recommend LT4 treatment when TSH values are above $4.0 \mathrm{mIU} / \mathrm{L}$ or ULRR $(1, \varnothing \varnothing \mathrm{OO})$.

\section{Thyroid Disorders and Male Subfertility}

Benign thyroid diseases (namely, hyperthyroidism, hypothyroidism, and TAI) have all been associated with adverse effects on male fertility. In case of thyroid malignancies, treatment with radioactive iodine (RAI) may have adverse effects on male fertility, and it has been suggested that thyroid malignancies per se might be more prevalent in men with azoospermia. However, unlike the evidence regarding female subfertility and thyroid diseases, the evidence regarding male subfertility and thyroid diseases is limited.

\section{Thyroid Dysfunction and Male Subfertility}

TH may influence male fertility both prenatally, by intervening on Sertoli cell maturing [31], and postnatally, having an effect on Leydig cell differentiation and steroidogenesis [32]. It has been reported that $7.4 \%$ of men of subfertile couples may present $\mathrm{SCH}$ and $3.7 \%$ subclinical hyperthyroidism, respectively [33]. Both conditions are believed to reduce mitochondrial activity and increase 
oxidative stress, thus negatively influencing male fertility. Interestingly, erectile function seems to be dependent on $\mathrm{TH}$ concentrations, so that decreased $\mathrm{TH}$ concentrations is associated with delayed ejaculation, whereas increased $\mathrm{TH}$ concentrations above the normal range are associated with premature ejaculation [34].

A large number of studies have demonstrated adverse effects of hypothyroidism on male fertility in foetal, early neonatal, or even adult life. Increased abnormalities in sperm morphology and motility have been described in case of prolonged $\mathrm{OH}$ in adults, though consistency among study results is lacking concerning $\mathrm{SCH}$, possibly due to heterogeneity among study samples [35]. Furthermore, in a study including men with abnormal semen parameters versus a group with normal semen characteristics, no difference in the prevalence of $\mathrm{SCH}$ was noted [36].

Subfertile hyperthyroid men commonly present with symptoms in relation to impaired libido, increased oestrogens (gynaecomastia), and erectile dysfunction, including premature ejaculation. Hyperthyroidism has also been associated with abnormal sperm parameters, namely, decreased sperm motility [37] and abnormal morphology [38]. In one study, TSH and FT4 concentrations were not correlated with sperm motility or morphology, and no difference was found among men with $\mathrm{SCH}$ and subclinical hyperthyroidism, though FT3 levels were positively associated with sperm count and other ultrasound parameters [33]. These observations have been based on small studies that included both fertile and subfertile men and are rather historic. In any case, treating hyperthyroidism seems to improve sperm parameters, even if not restoring all sperm parameters to normal [39].

Regarding TAI, it is known to be the most important cause of hypo- and hyperthyroidism, and as such, it can lead to the above-mentioned changes in the reproductive hormones and semen parameters. Furthermore, in a longitudinal registry-based study with an 8-year follow-up, subfertile men (postvasectomy excluded) developed more TAI in comparison with age-matched controls (hazard ratio [HR] 1.60, 95\% CI: 1.02-2.52) [40]. The underlying reasons for this association may be due to lower androgen levels in subfertile men, but TAI can also be a marker/reflection of a more generalized underlying immune disorder also causing the subfertility. Noteworthy concerning the latter hypothesis is the higher prevalence of other autoimmune disorders (lupus, rheumatoid arthritis, and others) too [40]. However, in one study, the prevalence of TAI was not different between subfertile and fertile men [36].

Management of Thyroid Disorders and Assisted Reproduction
Chapter-Specific Recommendations/Suggestions

We recommend against the systematic screening for thyroid disorders (TSH and TPOAb) in males of subfertile couples $(1, \varnothing \varnothing \varnothing O)$. We suggest screening for thyroid dysfunction (TSH) in men with ejaculation and erectile dysfunction and/or altered semen parameters (2, ØØOO). We recommend not postponing ART treatment (IVF/ ICSI) in case of subclinical or overt hypo- or hyperthyroidism in the male as long as sperm parameters are not severely affected $(1, \varnothing \varnothing \bigcirc)$.

\section{Thyroid Malignancies and Male Subfertility}

Epidemiological Data

In an analysis of the US Claims database, it was reported that subfertile men had an increased risk of thyroid malignancies, in comparison with controls (HR 1.52, 95\% CI: 1.01-2.30) [41]. In another large-scale epidemiological study, it was demonstrated that first- and second-degree relatives of men with azoospermia have twice the risk of developing thyroid cancer comparing to fertile population (HR 2.12, 95\% CI: 1.26-3.57; HR 1.57, 95\% CI: 1.032.39 , respectively), though no difference was detected among relatives of unselected subfertile men and fertile controls [42]. It has been suggested that men with (nonobstructive) azoospermia share common pathogen(et)ic steps with the development of thyroid cancers (i.e., presence of abnormal glycoprotein hormone alpha subunits and mutated thyroid receptors, in cases of subfertility and papillary cancer, respectively) $[42,43]$.

\section{RAI and Fertility Considerations}

It has been suggested that RAI can temporarily increase follicle-stimulating hormone (FSH) and have a negative impact on sperm parameters $[35,44]$. In a prospective multi-centre study where men with differentiated thyroid cancer were assessed before and 3 and 13 months after thyroid ablation (3.7 GBq), there was an increase in sperm chromosomal abnormalities (disomies or aneuploidies) at both time points (increasing from 3.2\% before RAI to $4.8 \% 3$ months and to $3.7 \% 13$ months after RAI; $p<0.01$ ) [44]. This is important as, at the time, it is suggested that men who need to take RAI are advised to postpone their fertility attempts for 120 days [45]. Larger studies are needed to confirm this finding before any major concern is conveyed to men who desire fertility and need to undertake RAI. In general, evidence is reassuring that there is no long-term impact on male fertility after a single RAI ablation though adverse effects are reported after multiple RAI treatments [46] and above $15 \mathrm{GBq}$ (400 $\mathrm{mCi})$ [47]. 
Chapter-Specific Recommendations/Suggestions

We recommend against screening all subfertile men and their relatives for thyroid cancer $(1, \varnothing \varnothing \varnothing O)$. We recommend that men who desire fertility and need to undergo an ablative dose of RAI to wait at least 120 days before attempting conception/giving sperm for IVF/ICSI $(1, \varnothing \varnothing \mathrm{OO})$. We do not recommend delaying RAI treatment for thyroid cancer for fertility reasons. However, it is advised that fertility issues/family planning are discussed before RAI treatment, and if multiple doses might be necessary (cumulative $>15 \mathrm{GBq} / 400 \mathrm{mCi}$ ), sperm banking should be offered $(1, \varnothing \varnothing \varnothing О)$.

Thyroid Disorders and Impact on Ovarian Reserve,

Fertilisation, and Embryo Development

Thyroid Disorders and Ovarian Reserve

Ovarian senescence is closely associated with the depletion of a woman's follicular pool during her reproductive lifespan. Although recently challenged by reports on ovarian stem cells, the concept that a female's oocyte supply is established during foetal development and cannot be replenished once her ovarian reserve is compromised due to injury or disease is still clinically acknowledged [48]. Therefore, particular attention needs to be drawn to pathophysiological mechanisms and exogenous factors that may negatively affect ovarian reserve and, thus, fertility potential.

Thyroid disease is more prevalent in females than in males and peaks during reproductive years, suggesting a relationship between thyroid function and steroidogenesis. Pathophysiological observations support this assumption: in humans, alterations in $\mathrm{TH}$ production may disrupt the hypothalamic-pituitary-ovarian axis and impair folliculogenesis $[48,49]$. The synergistic interaction between FSH and T3 enhances granulosa cell proliferation [50]. Thyroid hormone receptors and thyrotropin receptor and $\mathrm{TH}$ transporters are expressed in the ovary, and T3, T4, and TPOAb are present in follicular fluid [49]. Consequently, one may assume an interrelation between the thyroid and ovarian reserve.

Primary ovarian insufficiency (POI) is defined as loss of ovarian function before age 40 and affects about $1: 10,000$ women by age $20,1: 1,000$ by age 30 , and $1: 100$ by age 40 . Causative mechanisms for POI include genetic factors (20-25\%), autoimmune conditions (4-30\%), and iatrogenic factors (i.e., ovariectomy) though the majority of the cases remain idiopathic [50]. Increased prevalence of genetic alterations and autoimmune disease in women with DOR suggests that POI and DOR may represent different degrees of the same spectrum [51, 52].
In a prospective study in women suffering from POI, conducted at the National Institutes of Health in the USA, Hashimoto's thyroiditis was encountered in $37 \%$ of POI women with Turner syndrome (45XO) and in $15 \%$ of POI patients with 46,XX karyotype, a prevalence that significantly exceeded that in the female US population (i.e., 5.8\%, $p<0.001$; RR 3.0, 95\% CI: 2.3-3.7) [53]. The European Society of Human Reproduction and Embryology recommends screening for TAI in all women diagnosed with spontaneous POI [54]. Consequently, since women with POI/DOR have a higher prevalence of TAI, they might also have a higher prevalence of $\mathrm{SCH}$ [55].

\section{Chapter-Specific Recommendations/Suggestions}

We recommend screening women with POI and DOR for thyroid dysfunction (serum TSH) and autoimmunity $(1, \varnothing \varnothing \varnothing 0)$.

Ovarian reserve and thyroid disorders have also been linked and investigated in subfertile women. A retrospective evaluation of 2,568 Chinese females initiating ART showed significantly lower AMH concentrations and antral follicle counts and higher FSH levels in women aged $\geq 35$ years with SCH [56]. Although thyroid disease appears to negatively affect the ovarian reserve in subsets of women with (unexplained) infertility and advanced reproductive age, a Belgian study in 4,894 young women with and without fertility problems could not demonstrate an impact of TAI and hypothyroidism on AMH levels [57].

Another large cross-sectional study in Chinese subfertility patients supports the concept that TAI may be related to idiopathic DOR: 1,044 women were grouped to low, normal, and high ovarian reserve categories according to age-adjusted AMH levels. Women with DOR demonstrated higher percentages of TPOAb $(23.3 \%)$ when compared to counterparts with normal (14.6\%) and high ovarian reserve $(10.4 \% ; p=0.014)$ [58]. These findings correlate with the data in the study by Weghofer et al. [8] in which significantly lower AMH levels were measured in women of advanced reproductive age and TSH levels $>3.0 \mathrm{mIU} / \mathrm{L}$. A prospective US study in 436 patients confirms these observations, reporting lower antral follicle counts in women with unexplained subfertility, DOR, and TPOAb ( -2.3 follicles, $95 \% \mathrm{CI}:-3.8$ to $-0.5 ; p=0.01$ ) [59]. Only limited research was undertaken to answer the question whether LT4 supplementation exerts beneficial effects on functional ovarian reserve. In one paper, increasing AMH levels were shown in women with TAI and TSH levels $>2.5 \mathrm{mIU} / \mathrm{L}$ after LT4 supplementation, suggesting a potential benefit on ovarian function [60]. Fur- 
ther research is needed to investigate whether LT4 improves in vitro ART outcomes such as the oocyte and embryo quality, the fertilisation rate (FR), and ultimately the (spontaneous) pregnancy rates.

\section{Chapter-Specific Recommendations/Suggestions}

We recommend screening subfertile women with unexplained subfertility or in their later reproductive years (i.e., $\geq 35$ years) for thyroid dysfunction (serum TSH) and autoimmunity $(1, \varnothing \varnothing \varnothing \mathrm{O})$. We suggest LT4 treatment in subfertile women with TAI and serum TSH $>2.5 \mathrm{mIU} / \mathrm{L}$ on a case-by-case basis to allow for optimized ovarian reserve $(2, \varnothing \varnothing \mathrm{\varnothing O})$.

\section{RAI and Fertility Considerations}

Recent reports on a potential negative impact of RAI therapy on ovarian reserve have raised a lot of attention. In 3 prospective studies, serial AMH measurements were performed prior to RAI therapy and regularly thereafter for up to 48 months [61-63]. In a Dutch study that included 65 women with a mean age of 32 years, AMH levels significantly declined during the first 12 months (i.e., $-55 \%)$ and stabilized thereafter in the single RAI group, while a further decline was demonstrated (i.e., $-85 \%$ after 48 months) after multiple RAI treatments. The steepest decrease was observed in women aged 35 years and above [62]. Yaish et al. [61] showed comparable results with a nadir at 3 months after treatment and a loss of about $30 \%$ from baseline after 12 months. Whether RAI treatment for well-differentiated thyroid cancers was related to lower birth rates was evaluated in a large US registry-based study of 18,850 women. While comparable birth rates were observed in the whole cohort, women aged 35-39 years experienced a $29 \%$ reduction in live births after RAI treatment $(p<0.01)$. Time to live birth was prolonged in women aged $20-39$ years $(p<0.0001)$ [63].

\section{Chapter-Specific Recommendations/Suggestions}

We recommend that RAI treatment for thyroid cancer is not delayed for fertility reasons. However, women (especially $>35$ years) should be informed on the impact of RAI on the LBR $(1, \varnothing \varnothing \varnothing O)$.

\section{Thyroid Disorders and Ovarian Retrieval Rate/}

Fertilisation/Embryo Quality

An increased prevalence of TAI (mainly TPOAb) is reported in women with recurrent pregnancy loss and subfertility and associated with lower AMH levels [16, 64]. This relationship raises the possibility that thyroid disease may negatively affect ovarian function, fertilisa-

Management of Thyroid Disorders and Assisted Reproduction tion potential, and embryo development. One of the major in vitro outcomes of an ART procedure is the NOR that closely reflects a woman's ovarian reserve.

In the meta-analysis by Busnelli et al. [15], TAI was not associated with the NOR, and these data were confirmed in a recent study by Poppe et al. [17]. In the latter study, thyroid function as such was not associated with NOR either: parallel findings to the study by Weghofer et al. [65] some years before. In a meta-analysis on the impact of LT4 on ART outcomes, the NOR was not improved [11].

Scarce evidence exists on the impact of thyroid function on the FRs. Cramer et al. [66] describe significant associations between higher TSH levels $(>3.9 \mathrm{mIU} / \mathrm{L})$ and fertilisation failure in 509 IVF patients, a relationship that remains intact when controlled for confounders. In a meta-analysis by Velkeniers et al. [11], it was shown that LT4 treatment improved the FRs in women with TSH levels $>4.0 \mathrm{mIU} / \mathrm{L}$.

In a small prospective study, Monteleone et al. [67] detected TgAb and TPOAb in follicular fluid of all subfertile patients with TAI, while none were observed in women without TAI. FRs were $63 \%$ in women with TAI and $72 \%$ in negative controls $(p<0.05)$. IVF and ICSI were applied in comparable proportions between both groups. In women with TAI, pregnancy occurred exclusively after ICSI, while controls achieved pregnancy after IVF and ICSI [67]. This observation is interesting to note as it may point towards a pathophysiological role of thyroid antibodies in the course of gamete development. In a model of female TPO-immunized mice, Lee et al. [68] show TPOAb on the surface of their preimplantation embryos. It is tempting to speculate that thyroid antibodies may also bind antigens expressed in the zona pellucida, hence impairing FRs [67]. This hypothesis may also explain why a meta-analysis by Busnelli et al. [15] demonstrated comparable FRs among women with and without TAI (all patients underwent ICSI). These assumptions are further supported by Zhong et al. [69], who analyzed 12,990 oocytes produced in 1,218 ART cycles after IVF and ICSI. They showed decreased FRs of $64 \%$ in women with TAI versus $74 \%$ in negative controls $(p<0.001)$ [69]. However, it should be noted that thyroid function was not determined in all patients. Poppe et al. [17] recently performed a meta-analysis on ART outcomes in women with and without TAI who exclusively underwent ICSI. FRs of 1,196 oocytes from TAI-positive and 6,200 oocytes from TAI-negative women were comparable (OR 1.02, 95\% CI: 0.89-1.16). Even more important, comparable miscarriage rates were observed, suggesting that ICSI may over- 
come the impeding effects of thyroid antibodies on oocytes and embryos [17]. However, before recommending the systematical application of ICSI in women with TAI, head-to-head studies are warranted comparing FRs in women with TAI treated either with IVF or ICSI and with corrections for woman's age, cause of subfertility, male parameters, and thyroid function.

\section{Chapter-Specific Recommendations/Suggestions}

We suggest offering ICSI for women with evidence of TAI as the preferred fertilisation method in the course of assisted reproduction $(2, \varnothing \varnothing О О)$.

The complexity of embryogenesis creates challenges to untangle the impact of thyroid function and autoimmunity on embryo development. Weghofer et al. [65] demonstrated poorer embryo quality in women with TAI and DOR despite normal TSH. Their findings of distinct effects of TAI and thyroid function on embryogenesis are supported by Monteleone et al. [67], who show significantly reduced rates of grade $\mathrm{A}$ embryos in the presence of TAI. An Italian cohort study underscores these data, reporting smaller proportions of good-quality embryos in TAI-positive women when compared to negative controls [70]. However, in a recent paper by Poppe et al. [12], no impact of thyroid disorders (TAI and SCH) was observed on embryo quality. Differences in study results can be due to patient selection or methodological issues in the scoring systems for embryo quality.

Whether LT4 treatment can alleviate the unfavourable influence of SCH or TAI on embryogenesis has not been fully elucidated. In one study among women with TSH $>4.0 \mathrm{mIU} / \mathrm{L}, \mathrm{LT} 4$ supplementation was capable of increasing the number of top-quality embryos [13]. Animal models support these findings, reporting higher cleavage and blastocyst formation rates in bovine embryos co-cultured with T3 and T4 [71]. One may assume that these positive effects on embryo quality could translate to and at least partially explain the decrease in miscarriage risk in women with SCH/TAI after LT4 supplementation [72], though definite conclusions can only be drawn in large-scale studies reporting on in vitro and clinical ART outcomes.

\section{Chapter-Specific Recommendations/Suggestions}

We recommend LT4 treatment in women with TAI and TSH levels $>4.0 \mathrm{mIU} / \mathrm{L} / \mathrm{ULRR}$ to keep TSH levels $<2.5 \mathrm{mIU} / / \mathrm{L}(1, \varnothing \mathrm{OOO})$. We suggest LT4 treatment in subfertile women with TAI and TSH levels $>2.5 \mathrm{mIU} / \mathrm{L}$ on a case-by-case basis to allow for optimized embryo development $(2, \varnothing \mathrm{OOO})$.

\section{Thyroid Function and OS}

Controlled OS is an integral part of ART, initiated with a pituitary downregulation with either $\mathrm{GnRH}$ analogues or antagonists, followed by OS with Gn [73], and terminated with a single injection of human chorionic gonadotropin (hCG) for ovulation induction. OS induces a rapid and supraphysiologic increase of serum E2 (4,000-6,000 $\mathrm{ng} / \mathrm{L}$ ) that reaches levels similar to those observed in the second part of pregnancy.

E2 rise results in an excess of TBG production and sialylation by the liver [74], leading to a reduced clearance rate of TBG [75] and ultimately in a decrease in free TH. In addition, a direct effect of the high E2 levels on thyrotropin-releasing hormone has been described, and all these mechanisms together can explain an increase in TSH levels due to OS [76]. In approximately one out of 3 euthyroid patients, serum TSH levels exceeded $2.5 \mathrm{mIU} / \mathrm{L}$ during ART cycles, and the TSH elevation can last 1-3 months after OS [74, 76-82].

The rate of patients with TSH $>2.5 \mathrm{mIU} / \mathrm{L}$ as well as the magnitude of the TSH increase is more pronounced in treated hypothyroid patients $[81,82]$, likely as a consequence of a reduced ability of the thyroid gland to adapt to the increased demand resulting from OS [82]. Accordingly, during OS, patients with positive TPOAb, due to the impaired thyroid function reserve, show increased TSH values and decreased FT4 levels with respect to TPOAb-negative women [74]. In euthyroid state and absent thyroid antibodies, the net effect of OS is considered negligible [76, 78]. In 1 study, fluctuations in FT4 and TSH concentrations had no impact on clinical ART outcomes, though the TPOAb status was not taken into account in that study [83].

Nowadays, hyperstimulation syndrome (HS) is exceptional. In women without thyroid disorders (no antibodies and not on LT4), HS is associated with a TSH rise indistinguishable from that experienced by women undergoing OS without HS and has no impact on the possible development of hypothyroidism [84]. On the other hand, $\mathrm{HS}$ can lead to severe $\mathrm{OH}$ in women with underlying TAI [85].

Another effect of OS on thyroid function to be considered is that related to hCG administration. It is well known that TSH and hCG, as well as their respective receptors, share structural homologies; as a result, the administration of hCG is predicted to exert a thyrotropic effect that in turn induces a reduction of TSH levels [86].

A Dutch study of $>7,000$ patients from 2 populationbased prospective cohorts demonstrated that the functional response to hCG is different between patients with 
or without TPOAb. Healthy patients show a reduction of TSH values and a proportional FT4 increase, whereas the functional trend of patients with TAI is impaired, being characterized by blunted TSH and T4 response [87]. Whether these data can be extrapolated to lower concentrations of hCG as used in ovulation induction remains to be determined.

The net result of these physiological or para-physiological effects of OS in women with TAI, treated or untreated with LT4, is a decrease in FT4 levels and an increase of TSH levels (due to decrease in FT4, not counteracted by the hCG increase). This is particularly evident in patients with TSH levels $>2.5 \mathrm{mIU} / \mathrm{L}$ before OS and might be a reason to adapt pre-OS dosage of LT4 to prevent hypothyroidism during early pregnancy stages $[10,82]$.

Recently, the possible impact of LT4 treatment on pregnancy outcome in euthyroid women with TAI has been evaluated in 600 Chinese cases undergoing ART [18] and in 952 British cases either on subfertility treatment or not [29]. In both studies, LT4 did not reduce miscarriage rates or increased live births.

As a conclusion, OS negatively alters thyroid function in women with hypothyroidism and/or TAI. The effects seem to last up to 3 months after treatment, though studies with longer follow-up are required for definite conclusions. Since adverse pregnancy outcomes have been associated with inadequately or untreated maternal hypothyroidism [4], the serial evaluation of thyroid function in women with treated hypothyroidism or euthyroid with TAI undergoing OS should be performed, starting from the second hCG measurement if the woman is pregnant (which is $\sim 6$ weeks after the start of OS or 3 weeks after the ovulation induction). Serial testing of thyroid function is likely not needed for euthyroid women without TAI, unless they are treated with LT4.

LT4 treatment might be considered for TSH levels $>2.5$ $\mathrm{mIU} / \mathrm{L}$ with TAI and should be started for TSH levels $>4.0$ $\mathrm{mIU} / \mathrm{L}$ or $>$ ULRR. Finally, more studies are required to investigate the impact of OS in women with increased $\mathrm{TgAb}$ levels and/or sonographic criteria of TAI and no TPOAb.

Chapter-Specific Recommendations/Suggestions

We recommend checking TSH levels after OS (in case of pregnancy, the day of the second/confirmatory hCG measurement) in women with TAI during LT4 treatment or after the initiation of it $(1, \varnothing \varnothing \varnothing O)$. We do not recommend serum TSH monitoring after OS for euthyroid women without TAI, unless treated with LT4 $(1, \varnothing \varnothing \varnothing O)$. We recommend adjusting LT4 dosage in women already

Management of Thyroid Disorders and Assisted Reproduction treated for (subclinical) hypothyroidism before OS to keep serum TSH levels $<2.5 \mathrm{mIU} / \mathrm{L}(1, \varnothing \varnothing O O)$. We suggest treating TAI-positive women with TSH levels $>2.5$ and $<4.0 \mathrm{mIU} / \mathrm{L} / \mathrm{ULRR}$ with a low dose of LT4 (usually $25-50 \mu \mathrm{g}$ daily) before OS on a case-by-case basis (2, $\varnothing \varnothing \mathrm{OO})$. We recommend treating TAI-positive women with TSH levels $>4.0 \mathrm{mIU} / \mathrm{L} / \mathrm{ULRR}$ before OS to keep serum TSH levels $<2.5 \mathrm{mIU} / \mathrm{L}(1, \varnothing \varnothing \mathrm{OO})$. We suggest treating TAI-negative women with TSH levels $>4.0$ $\mathrm{mIU} / \mathrm{L} / \mathrm{ULRR}$ before OS $(2, \varnothing \varnothing \mathrm{OO})$. We do not recommend treating euthyroid women without TAI before OS (1, ØООО).

\section{Thyroid Disorders and ART (IVF/ICSI) Outcomes}

One of the remaining questions in the field is whether LT4 administration in euthyroid women with TAI improves ART outcomes. Pooled data of women undergoing ART (both IVF and ICSI) have suggested that women with TAI $(n=299)$ are at increased risk of miscarriage and have lower LBRs compared to women without TAI ( $n=$ 1,931) [15]. In contrast, a more recent meta-analysis focussing solely on women undergoing ICSI did not show differences in miscarriage and LBRs between women with ( $n=114$ for outcome miscarriage and $n=95$ for outcome LBR) and without ( $n=651$ for outcome miscarriage and $n=531$ for outcome LBR) TAI [17]. The reasons why the impact of TAI on the miscarriage rate was absent in the latter meta-analysis might have been due to inclusion of ICSI only as the type of ART. Considering the association, it seems justified to determine if treatment with LT4 can improve ART outcome in women with TAI undergoing ART. This question has been addressed in a Cochrane systemic review including studies up till April 2019 [88]. Two studies could be included that randomized a total of 686 euthyroid women (TSH levels $<4.2$ and $<4.8 \mathrm{mIU} / \mathrm{L}$, respectively) to treatment with LT4 or placebo/no treatment $[18,89]$. LT4 treatment had no effect on live birth, clinical pregnancy, or miscarriage. The quality of evidence for the outcome live birth was low.

\section{Chapter-Specific Recommendations/Suggestions}

We suggest that euthyroid women with TAI undergoing IVF/ICSI should not be treated systematically with LT4 (2, ØØОO).

Another recurrent question is whether LT4 treatment of SCH improves ART outcomes. The majority of data on SCH (defined as a serum TSH $>2.5 \mathrm{mIU} / \mathrm{L}$ ) and ART outcomes suggest that there is no association with lower LBRs or higher miscarriage rates compared to TSH $<2.5 \mathrm{mIU} / \mathrm{L}$ [90-93]. Nevertheless, women with 


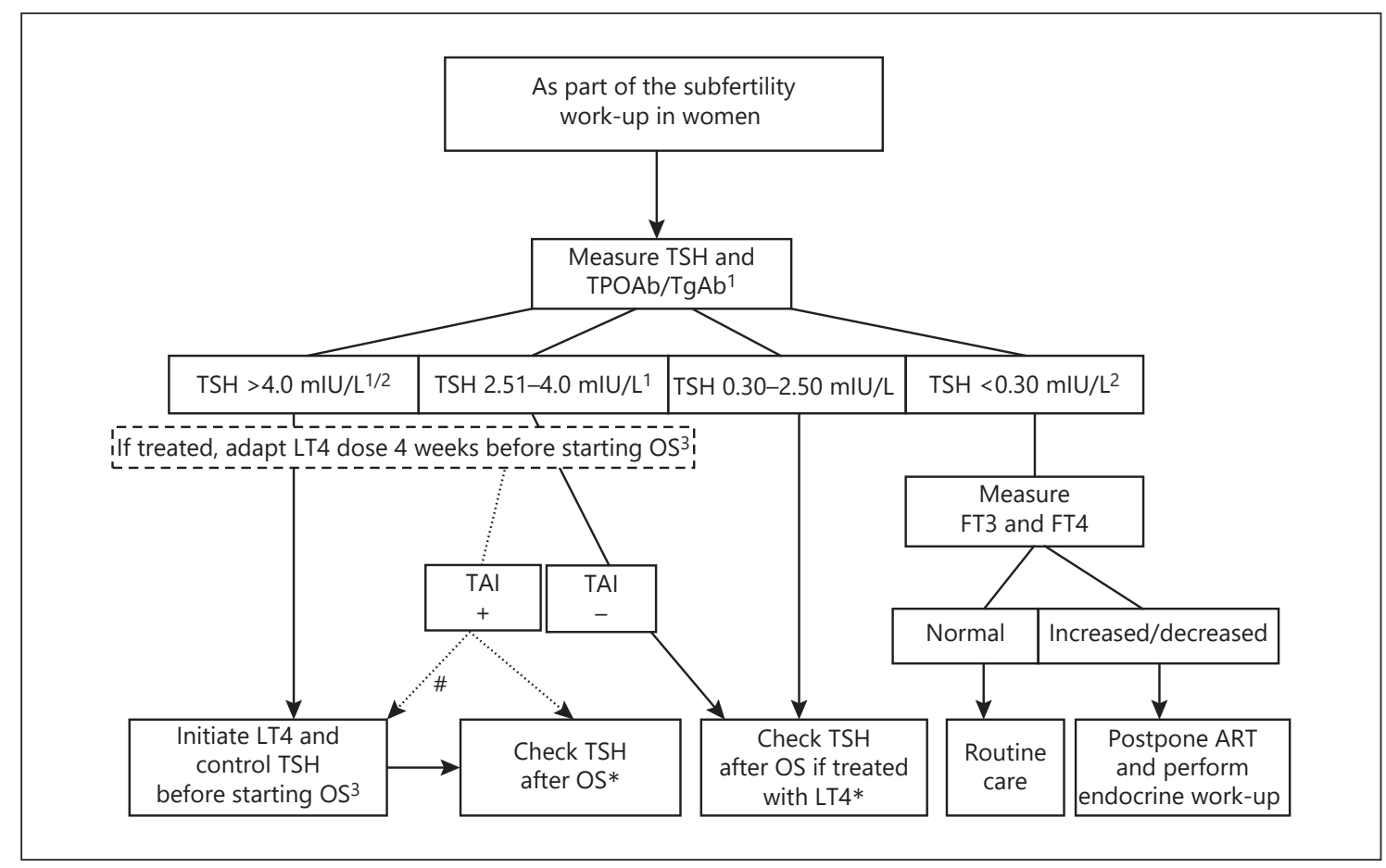

Fig. 1. Algorithm for workup and management of thyroid disorders in women of subfertile couples starting an ART procedure. ${ }^{1}$ If not possible for local terms, then measure TgAb in case TSH $>2.5$ $\mathrm{mIU} / \mathrm{L}$ and negative TPOAb/look for sonographic criteria of TAI if available. ${ }^{2}$ Or above/below the reference range of the assay for non-pregnant women or institutional population-specific values. ${ }^{3} \mathrm{LT} 4$ dose depending on baseline TSH level and body weight; start $25 \mu \mathrm{g}$ when TSH 2.51-4.0 mIU/L $\rightarrow$ target TSH $<2.5 \mathrm{mIU} / \mathrm{L}$. ${ }^{\#} \mathrm{De}-$

more pronounced elevation of TSH might still benefit from LT4 treatment. The same Cochrane systemic review as mentioned before [88] identified 2 studies that met the inclusion criteria $[13,21]$, but the results of one of those studies were not used because the integrity of the data could not be verified. The other study randomized 64 women (with and without TAI) with TSH $>4.5$ $\mathrm{mIU} / \mathrm{L}$ scheduled for IVF/ICSI to LT4 or no treatment. LT4 treatment was associated with $27-100 \%$ chance of live birth compared to $25 \%$ in the control group. The level of evidence was downgraded for imprecision from low to very low.

Chapter-Specific Recommendations/Suggestions

We suggest that LT4 treatment is initiated before OS in women with TSH levels $>4.0 \mathrm{mIU} / \mathrm{L} / \mathrm{ULRR}$ undergoing IVF/ICSI (2, ØOOO). cide to treat on a case-by-case basis (cf text for details). *In case of pregnancy, the day of the second/confirmatory hCG measurement. TAI, thyroid autoimmunity; $\mathrm{TgAb}$, thyroglobulin antibodies; TPOAb, thyroid peroxidase antibodies; LT4, levothyroxine; hCG, human chorionic gonadotropin; OS, ovarian stimulation; ART, assisted reproductive technology. The figure is reproduced from Unuane and Poppe (Female infertility: do we forget the thyroid? J Endocrinol Invest. 2015) with permission from Springer.

\section{Screening/Management in Daily Practice}

We suggest screening for thyroid dysfunction (TSH) and autoimmunity (TPOAb) in women of subfertile couples planning an ART treatment. The presence of increased TgAb levels can be verified in women with TSH levels $>2.5 \mathrm{mIU} /$ and no increased TPOAb levels.

According to the general principles of screening by Wilson and Jungner, the case of subfertility and ART fulfils many of the prerequisites [94]. The presence of increased TPOAb levels may identify women at risk for developing hypothyroidism after OS or during gestation and be a predictive marker for the development of postpartum thyroiditis [95]. Furthermore, women with PCOS, POI, and idiopathic subfertility have a higher prevalence of TAI and serum TSH levels compared with fertile women $[6,9,25]$. Serum TSH levels $>3.5 \mathrm{mIU} / \mathrm{L}$ are associated with impaired ART outcomes, and LT4 treat- 
Table 1. Summary of the guideline recommendations/suggestions

\begin{tabular}{|c|c|c|}
\hline R1 & $\begin{array}{l}\text { We recommend that all women seeking medical advice for subfertility should be screened for TSH and TPOAb. TgAb can be } \\
\text { added systematically according to the local regulatory authority rules }\end{array}$ & $1, \varnothing \varnothing \varnothing 0$ \\
\hline $\mathrm{R} 2$ & $\begin{array}{l}\text { We suggest that subfertile women with TSH levels }>2.5 \mathrm{mIU} / \mathrm{L} \text { and without increased TPOAb levels (according to the local } \\
\text { reference range) are screened for the presence of increased TgAb levels if not yet done at initial workup }\end{array}$ & 2, ØØОО \\
\hline $\mathrm{R} 3$ & We recommend against the systematic screening for thyroid disorders (TSH and TPOAb) in males of subfertile couples & $1, \varnothing \varnothing \varnothing 0$ \\
\hline R4 & $\begin{array}{l}\text { We suggest screening for thyroid dysfunction (TSH) in men with ejaculation and erectile dysfunction and/or altered semen } \\
\text { parameters }\end{array}$ & 2, ØØОО \\
\hline R6 & We recommend against screening all subfertile men and their relatives for thyroid cancer & $1, \varnothing \varnothing \varnothing 0$ \\
\hline R7 & $\begin{array}{l}\text { We recommend men who desire fertility and need to undergo an ablative dose of RAI to wait at least } 120 \text { days before attempting } \\
\text { conception/giving sperm for IVF/ICSI }\end{array}$ & $1, \varnothing \varnothing 00$ \\
\hline $\mathrm{R} 10$ & $\begin{array}{l}\text { We suggest offering ICSI for women with evidence of TAI as the preferred fertilisation method in the course of assisted } \\
\text { reproduction }\end{array}$ & 2, ØØОО \\
\hline R11 & We recommend that LT4 treatment should be started promptly in women in case of overt thyroid dysfunction & $1, \varnothing \varnothing \varnothing 0$ \\
\hline $\mathrm{R} 12$ & We recommend LT4 treatment in women with TAI and TSH levels $>4.0 \mathrm{mIU} / \mathrm{L} / \mathrm{ULRR}$ to keep serum TSH levels $<2.5 \mathrm{mIU} / \mathrm{L}$ & $1, \varnothing \varnothing 00$ \\
\hline $\mathrm{R} 13$ & We recommend LT4 treatment in women without TAI and TSH levels $>4.0 \mathrm{mIU} / \mathrm{L} / \mathrm{ULRR}$ to keep serum TSH levels $<2.5 \mathrm{mIU} / \mathrm{L}$ & $1, \varnothing 000$ \\
\hline $\mathrm{R} 14$ & $\begin{array}{l}\text { We recommend adjusting LT4 dosage in women already treated for (subclinical) hypothyroidism before OS to keep serum TSH } \\
\text { levels }<2.5 \mathrm{mIU} / \mathrm{L}\end{array}$ & $1, \varnothing \varnothing 00$ \\
\hline R15 & $\begin{array}{l}\text { We suggest LT4 treatment in women with TAI and TSH levels }>2.5 \text { and }<4.0 \mathrm{mIU} / \mathrm{L} / \mathrm{ULRR} \text { with a low dose of LT4 (usually } 25-50 \\
\mu \mathrm{g} \text { daily) before OS on a case-by-case basis }{ }^{\mathrm{a}}\end{array}$ & 2, ØØОО \\
\hline
\end{tabular}

TSH, thyroid-stimulating hormone; TPOAb, thyroid peroxidase antibodies; TgAb, thyroglobulin antibodies; ART, assisted reproductive technology; IVF, in vitro fertilisation; ICSI, intracytoplasmic sperm injection; RAI, radioactive iodine; POI, primary ovarian insufficiency; DOR, diminished ovarian reserve; ULRR, upper limit of the reference range; OS, ovarian stimulation; hCG, human chorionic gonadotropin; TAI, thyroid autoimmunity; LT4, levothyroxine; LBR, live birth rate. ${ }^{\text {a }}$ Recurrent miscarriage, age $>35$ years, and ovarian causes of subfertility.

ment can increase LBRs in women with TSH levels $>4.0$ $\mathrm{mIU} / \mathrm{L}[11,14]$.

In summary, testing for serum TSH and antibodies is easy and widely available. The prevalence of thyroid disorders is high in subfertile women and associated with altered pregnancy outcomes that can be treated with a safe treatment (LT4) able to improve ART outcomes.

The statement from the American Society for Reproductive Medicine and the American Thyroid Association guidelines also mentions that the available data support the routine measurement of TSH in subfertile women attempting pregnancy, but to check for increased TPOAb levels only if TSH levels are $>2.5 \mathrm{mIU} / \mathrm{L}[45,96]$. Universal screening in subfertile women cannot currently be recommended because of the limited number of RCTs; to the best of our knowledge, the study by Wang et al. [18] is the only one. It was performed in euthyroid subfertile women with TAI and showed no beneficial effect of LT4 on the 
pregnancy outcomes. Therefore, we cannot recommend systematic treatment of all euthyroid women $(\mathrm{TSH}>2.5$ $\mathrm{mIU} / \mathrm{L}$ ) with increased TPOAb levels. In this particular group, a decision to treat can be made on a case-by-case basis, taking into account factors such as ovarian causes of subfertility (DOR and POI), older age ( $>35$ years), a history of recurrent miscarriage, or high levels of thyroid antibodies even if the woman is already considered as TAI positive $[18,97]$. Future studies should define these criteria more clearly.

In Figure 1, an algorithm is proposed for the workup and management of thyroid disorders in women of subfertile couples starting an ART procedure. In males with ejaculation problems, erectile dysfunction, and/or altered semen parameters, we suggest screening for thyroid dysfunction (TSH).

\section{Conclusions and Perspectives}

Thyroid dysfunction and autoimmunity are associated with female and idiopathic subfertility and many aspects of the subsequently applied ART treatment. Since the evidence on the treatment of subfertile women with $\mathrm{SCH}$ with LT4 is scarce and based on small or low-quality studies, many questions remain unanswered, and more RCTs are necessary. Our current practice could be improved by determining an optimal TSH cutoff value at which LT4 should be initiated and targeted at. The better understanding of genetics underlying thyroid function and the determination (use) of each individual TSH setpoint might shed more light on these aspects in the near future. The diagnosis of TAI as such needs to be optimized by investigating the impact of increased TgAb, TPOAb cutoffs as they are provided by the manufacturers, and finally sonographic features of TAI in relation to ART outcomes. More long-term follow-up studies are needed to investigate better the impact of OS on thyroid function according to the different schemes used.

Finally, when ART outcomes are investigated, corrections should be made for baseline characteristics such as obesity, age, and tobacco use, for the type of ART (ICSI vs. IVF), and last but not least for male parameters (demographics and semen). More fundamental research is warranted on (human) oocytes/embryos to determine whether TH and TAI in the follicular fluid have a direct detrimental effect on oocyte/embryo development or whether TAI is rather an epiphenomenon of a general immune disorder that can lead to impaired embryo implantation and/or clinical pregnancy. This understanding would help to determine whether besides ART and LT4 other treatments could improve ART outcomes in euthyroid women with TAI. In males with non-obstructive azoospermia, the possibility of a higher prevalence of thyroid cancer needs to be investigated further.

This guideline and recommendations should be evaluated together with the clinical judgement, individual decision-making, and the wishes of the patient, in order to give the best care. The recommendations that form this guideline are presented in Table 1.

\section{Acknowledgements}

The ETA members who dedicated their time to improve this guideline paper are acknowledged.

\section{Statement of Ethics}

This work was conducted ethically in accordance with the World Medical Association Declaration of Helsinki. This type of research did not need ethics committee approval.

\section{Conflict of Interest Statement}

K.P. received lecture fees from Berlin-Chemie AG Co. in 2018, 2019, and 2020. The authors declare no other support from any organization in relation to the current work.

\section{Funding Sources}

This research received no grant funding.

\section{Author Contributions}

All authors gathered information, interpreted data, and wrote a chapter of the guideline. K.P. coordinated this process, and then the final version of the manuscript was accepted by all authors.

\section{References}

1 Valdes S, Maldonado-Araque C, LagoSampedro A, Lillo JA, Garcia-Fuentes E, Perez-Valero V, et al. Population-based national prevalence of thyroid dysfunction in Spain and associated factors: Di@bet.es study. Thyroid. $2017 \mathrm{Feb}$;27(2):156-66.

2 Vander Borght M, Wyns C. Fertility and infertility: definition and epidemiology. Clin Biochem. 2018 Dec;62:2-10. 
3 Präg P, Mills MC. Cultural determinants influence assisted reproduction usage in Europe more than economic and demographic factors. Hum Reprod. 2017 Nov;32(11):230514.

4 Krassas GE, Poppe K, Glinoer D. Thyroid function and human reproductive health. Endocr Rev. 2010 Oct;31(5):702-55.

5 Colicchia M, Campagnolo L, Baldini E, Ulisse S, Valensise H, Moretti C. Molecular basis of thyrotropin and thyroid hormone action during implantation and early development. Hum Reprod Update. 2014 Nov-Dec;20(6): 884-904.

6 van den Boogaard E, Vissenberg R, Land JA, van Wely M, Ven der Post JA, Goddijn M, et al. Significance of (sub)clinical thyroid dysfunction and thyroid autoimmunity before conception and in early pregnancy: a systematic review. Hum Reprod Update. 2016 Jun; 22(4):532-3.

7 Romitti M, Fabris VC, Ziegelmann PK, Maia AL, Spritzer PM. Association between PCOS and autoimmune thyroid disease: a systematic review and meta-analysis. Endocr Connect. 2018 Oct;7(11):1158-67.

8 Weghofer A, Barad DH, Darmon S, Kushnir VA, Gleicher N. What affects functional ovarian reserve, thyroid function or thyroid autoimmunity? Reprod Biol Endocrinol. 2016 May;14(1):26

9 Grossmann B, Saur S, Rall K, Pecher AC, Hübner S, Henes J, et al. Prevalence of autoimmune disease in women with premature ovarian failure. Eur J Contracept Reprod Health Care. 2020 Feb;25(1):72-5.

10 Busnelli A, Vannucchi G, Paffoni A, Faulisi S, Fugazzola L, Fedele L, et al. Levothyroxine dose adjustment in hypothyroid women achieving pregnancy through IVF. Eur J Endocrinol. 2015 Oct;173(4):417-24

11 Velkeniers B, Van Meerhaeghe A, Poppe K, Unuane D, Tournaye H, Haentjens P. Levothyroxine treatment and pregnancy outcome in women with subclinical hypothyroidism undergoing assisted reproduction technologies: systematic review and meta-analysis of RCTs. Hum Reprod Update. 2013 May-Jun; 19(3):251-8.

12 Poppe K, Autin C, Veltri F, Sitoris G, Kleynen $\mathrm{P}$, Praet JP, et al. Thyroid disorders and in vitro outcomes of assisted reproductive technology: an unfortunate combination? Thyroid. 2020 Aug;30(8):1177-85.

13 Kim CH, Ahn JW, Kang SP, Kim SH, Chae HD, Kang BM. Effect of levothyroxine treatment on in vitro fertilization and pregnancy outcome in infertile women with subclinical hypothyroidism undergoing in vitro fertilization/intracytoplasmic sperm injection. Fertil Steril. 2011 Apr;95(5):1650-4.

14 Zhao T, Chen BM, Zhao XM, Shan ZY. Metaanalysis of ART outcomes in women with different preconception TSH levels. Reprod Biol Endocrinol. 2018 Nov;16(1):111.
15 Busnelli A, Paffoni A, Fedele L, Somigliana E. The impact of thyroid autoimmunity on IVF/ ICSI outcome: a systematic review and metaanalysis. Hum Reprod Update. 2016 Nov; 22(6):775-90

16 Thangaratinam S, Tan A, Knox E, Kilby MD Franklyn J, Coomarasamy A. Association between thyroid autoantibodies and miscarriage and preterm birth: meta-analysis of evidence. BMJ. 2011 May 9;342:d2616.

17 Poppe K, Autin C, Veltri F, Kleynen P, Grabczan L, Rozenberg S, et al. Thyroid autoimmunity and intracytoplasmic sperm injection outcome: a systematic review and meta-analysis. J Clin Endocrinol Metab. 2018 Mar 12.

18 Wang $\mathrm{H}$, Gao H, Chi H, Zeng L, Xiao W, Wang Y, et al. Effect of levothyroxine on miscarriage among women with normal thyroid function and thyroid autoimmunity undergoing in vitro fertilization and embryo transfer: a randomized clinical trial. JAMA. 2017 Dec;318(22):2190-8.

19 Swiglo BA, Murad MH, Schünemann HJ, Kunz R, Vigersky RA, Guyatt GH, et al. A case for clarity, consistency, and helpfulness: stateof-the-art clinical practice guidelines in endocrinology using the grading of recommendations, assessment, development, and evaluation system. J Clin Endocrinol Metab. 2008 Mar;93(3):666-73.

20 Barth JH, Luvai A, Jassam N, Mbagaya W, Kilpatrick ES, Narayanan D, et al. Comparison of method-related reference intervals for thyroid hormones: studies from a prospective reference population and a literature review. Ann Clin Biochem. 2018 Jan;55(1):107-12.

21 Abdel Rahman AH, Aly Abbassy H, Abbassy AA. Improved in vitro fertilization outcomes after treatment of subclinical hypothyroidism in infertile women. Endocr Pract. 2010 SepOct;16(5):792-7.

22 Hollowell JG, Staehling NW, Flanders WD, Hannon WH, Gunter EW, Spencer CA, et al. Serum TSH, T(4), and thyroid antibodies in the United States population (1988 to 1994): National Health and Nutrition Examination Survey (NHANES III). J Clin Endocrinol Metab. 2002 Feb;87(2):489-99.

23 Aghajanova L, Lindeberg M, Carlsson IB, Stavreus-Evers A, Zhang P, Scott JE, et al. Receptors for thyroid-stimulating hormone and thyroid hormones in human ovarian tissue. Reprod Biomed Online. 2009 Mar;18(3):33747.

24 Dyer SJ. International estimates on infertility prevalence and treatment seeking: potential need and demand for medical care. Hum Reprod. 2009 Sep;24(9):2379-3;

25 Poppe K, Velkeniers B, Glinoer D. The role of thyroid autoimmunity in fertility and pregnancy. Nat Clin Pract Endocrinol Metab. 2008 Jul;4(7):394-405.
26 Feldthusen AD, Pedersen PL, Larsen J, Toft Kristensen T, Ellervik C, Kvetny J. Impaired fertility associated with subclinical hypothyroidism and thyroid autoimmunity: the Danish general suburban population study. J Pregnancy. 2015;2015:132718.

27 Orouji Jokar T, Fourman LT, Lee H, Mentzinger K, Fazeli PK. Higher TSH levels within the normal range are associated with unexplained infertility. J Clin Endocrinol Metab. 2018 Feb;103(2):632-9.

28 Unuane D, Velkeniers B, Anckaert E, Schiettecatte J, Tournaye $\mathrm{H}$, Haentjens $\mathrm{P}$, et al. Thyroglobulin autoantibodies: is there any added value in the detection of thyroid autoimmunity in women consulting for fertility treatment? Thyroid. 2013 Aug;23(8):1022-8.

29 Dhillon-Smith RK, Middleton LJ, Sunner KK, Cheed V, Baker K, Farrell-Carver S, et al. Levothyroxine in women with thyroid peroxidase antibodies before conception. N Engl J Med. 2019 Apr;380(14):1316-25.

30 Rahnama R, Mahmoudi AR, Kazemnejad S, Salehi M, Ghahiri A, Soltanghoraee H, et al. Thyroid peroxidase in human endometrium and placenta: a potential target for anti-TPO antibodies. Clin Exp Med. 2020 Sep 26

31 Holsberger DR, Cooke PS. Understanding the role of thyroid hormone in Sertoli cell development: a mechanistic hypothesis. Cell Tissue Res. 2005 Oct;322(1):133-40.

32 Mendis-Handagama SM, Ariyaratne HB. Effects of thyroid hormones on Leydig cells in the postnatal testis. Histol Histopathol. 2004 Jul;19(3):985-97.

33 Lotti F, Maseroli E, Fralassi N, Degl'Innocenti $\mathrm{S}$, Boni $\mathrm{L}$, Baldi $\mathrm{E}$, et al. Is thyroid hormones evaluation of clinical value in the work-up of males of infertile couples? Hum Reprod. 2016 Mar;31(3):518-29.

34 Corona G, Jannini EA, Vignozzi L, Rastrelli G, Maggi M. The hormonal control of ejaculation. Nat Rev Urol. 2012 Sep;9(9):508-19.

35 Krassas GE, Markou KB. The impact of thyroid diseases starting from birth on reproductive function. Hormones. 2019 Dec;18(4): $365-81$.

36 Poppe K, Glinoer D, Tournaye H, Maniewski U, Haentjens P, Velkeniers B. Is systematic screening for thyroid disorders indicated in subfertile men? Eur J Endocrinol. 2006 Mar; 154(3):363-6.

37 Hudson RW, Edwards AL. Testicular function in hyperthyroidism. J Androl. 1992 MarApr;13(2):117-24.

38 Abalovich M, Levalle O, Hermes R, Scaglia $\mathrm{H}$ Aranda C, Zylbersztein C, et al. Hypothalamic-pituitary-testicular axis and seminal parameters in hyperthyroid males. Thyroid. 1999 Sep;9(9):857-63.

39 Krassas GE, Pontikides N, Deligianni V, Miras $\mathrm{K}$. A prospective controlled study of the impact of hyperthyroidism on reproductive function in males. J Clin Endocrinol Metab. 2002 Aug;87(8):3667-71. 
40 Brubaker WD, Li S, Baker LC, Eisenberg ML. Increased risk of autoimmune disorders in infertile men: analysis of US claims data. Andrology. 2018 Jan;6(1):94-8.

41 Eisenberg ML, Li S, Brooks JD, Cullen MR, Baker LC. Increased risk of cancer in infertile men: analysis of U.S. claims data. J Urol. 2015 May;193(5):1596-601.

42 Anderson RE, Hanson HA, Patel DP, Johnstone E, Aston KI, Carrell DT, et al. Cancer risk in first- and second-degree relatives of men with poor semen quality. Fertil Steril. 2016 Sep;106(3):731-8.

43 Fozzatti L, Kim DW, Park JW, Willingham MC, Hollenberg AN, Cheng SY. Nuclear receptor corepressor (NCOR1) regulates in vivo actions of a mutated thyroid hormone receptor $\alpha$. Proc Natl Acad Sci U S A. 2013 May; 110(19):7850-5.

44 Bourcigaux N, Rubino C, Berthaud I, Toubert ME, Donadille B, Leenhardt L, et al. Impact on testicular function of a single ablative activity of $3.7 \mathrm{GBq}$ radioactive iodine for differentiated thyroid carcinoma. Hum Reprod. 2018 Aug;33(8):1408-16.

45 Alexander EK, Pearce EN, Brent GA, Brown RS, Chen H, Dosiou C, et al. 2017 Guidelines of the American Thyroid Association for the diagnosis and management of thyroid disease during pregnancy and the postpartum. Thyroid. 2017 Mar;27(3):315-89.

46 Canale D, Ceccarelli C, Caglieresi C, Moscatelli A, Gavioli S, Santini P, et al. Effects of radioiodine treatment for differentiated thyroid cancer on testis function. Clin Endocrinol. 2015 Feb;82(2):295-9.

47 Haugen BR, Alexander EK, Bible KC, Doherty GM, Mandel SJ, Nikiforov YE, et al. 2015 American Thyroid Association management guidelines for adult patients with thyroid nodules and differentiated thyroid cancer: the American Thyroid Association guidelines task force on thyroid nodules and differentiated thyroid cancer. Thyroid. 2016 Jan;26(1): 1-133.

48 Eggan K, Jurga S, Gosden R, Min IM, Wagers AJ. Ovulated oocytes in adult mice derive from non-circulating germ cells. Nature. 2006 Jun;441(7097):1109-14.

49 Vissenberg R, Manders VD, Mastenbroek S, Fliers E, Afink GB, Ris-Stalpers C, et al. Pathophysiological aspects of thyroid hormone disorders/thyroid peroxidase autoantibodies and reproduction. Hum Reprod Update. 2015 May-Jun;21(3):378-87.

50 Coulam CB, Adamson SC, Annegers JF. Incidence of premature ovarian failure. Obstet Gynecol. 1986 Apr;67(4):604-6.

51 Weghofer A, Brill H, Feichtinger R, Barad D, Gleicher N. Does autoimmunity play a role in the pathophysiology of premature ovarian ageing? Reprod Biomed Online. 2008 Jun; 16(6):830-4.
52 Osuka S, Iwase A, Goto M, Takikawa S, Nakamura T, Murase T, et al. Thyroid autoantibodies do not impair the ovarian reserve in euthyroid infertile women: a cross-sectional study. Horm Metab Res. 2018 Jul;50(7):537-42.

53 Bakalov VK, Gutin L, Cheng CM, Zhou J, Sheth $\mathrm{P}$, Shah K, et al. Autoimmune disorders in women with Turner syndrome and women with karyotypically normal primary ovarian insufficiency. J Autoimmun. 2012 Jun;38(4): 315-21.

54 European Society for Human R, Embryology Guideline Group on POI, Webber L, Webber L, Davies M, Anderson R, Bartlett J, Braat D, et al. ESHRE Guideline: management of women with premature ovarian insufficiency. Hum Reprod. 2016 May;31(5):926-37.

55 Abalovich M, Mitelberg L, Allami C, Gutierrez S, Alcaraz G, Otero P, et al. Subclinical hypothyroidism and thyroid autoimmunity in women with infertility. Gynecol Endocrinol. 2007 May;23(5):279-83.

56 Rao M, Wang H, Zhao S, Liu J, Wen Y, Wu Z, et al. Subclinical hypothyroidism is associated with lower ovarian reserve in women aged 35 years or older. Thyroid. 2020 Jan;30(1):95105.

57 Polyzos NP, Sakkas E, Vaiarelli A, Poppe K, Camus M, Tournaye H. Thyroid autoimmunity, hypothyroidism and ovarian reserve: a cross-sectional study of 5000 women based on age-specific AMH values. Hum Reprod. 2015 Jul;30(7):1690-6.

58 Chen CW, Huang YL, Tzeng CR, Huang RL, Chen $\mathrm{CH}$. Idiopathic low ovarian reserve is associated with more frequent positive thyroid peroxidase antibodies. Thyroid. 2017 Sep;27(9):1194-200.

59 Korevaar TIM, Mínguez-Alarcón L, Messerlian C, de Poortere RA, Williams PL, Broeren MA, et al. Association of thyroid function and autoimmunity with ovarian reserve in women seeking infertility care. Thyroid. 2018 Oct; 28(10):1349-58.

60 Kuroda M, Kuroda K, Segawa T, Noh JY, Yoshihara A, Ito K, et al. Levothyroxine supplementation improves serum anti-Müllerian hormone levels in infertile patients with Hashimoto's thyroiditis. J Obstet Gynaecol Res. 2018 Apr;44(4):739-46.

61 Yaish I, Azem F, Gutfeld O, Silman Z, Serebro $\mathrm{M}$, Sharon $\mathrm{O}$, et al. A single radioactive iodine treatment has a deleterious effect on ovarian reserve in women with thyroid cancer: results of a prospective pilot study. Thyroid. 2018 Apr;28(4):522-7.

62 van Velsen EFS, Visser WE, van den Berg SAA, Kam BLR, van Ginhoven TM, Massolt ET, et al. Longitudinal analysis of the effect of radioiodine therapy on ovarian reserve in females with differentiated thyroid cancer. Thyroid. 2020 Apr;30(4):580-7.

$63 \mathrm{Wu}$ JX, Young S, Ro K, Li N, Leung AM, Chiu $\mathrm{HK}$, et al. Reproductive outcomes and nononcologic complications after radioactive iodine ablation for well-differentiated thyroid cancer. Thyroid. 2015 Jan;25(1):133-8.
64 Magri F, Schena L, Capelli V, Gaiti M, Zerbini F, Brambilla E, et al. Anti-Mullerian hormone as a predictor of ovarian reserve in ART protocols: the hidden role of thyroid autoimmunity. Reprod Biol Endocrinol. 2015 Sep 21; 13(1):106.

65 Weghofer A, Himaya E, Kushnir VA, Barad $\mathrm{DH}$, Gleicher N. The impact of thyroid function and thyroid autoimmunity on embryo quality in women with low functional ovarian reserve: a case-control study. Reprod Biol Endocrinol. 2015 May; 13;43.

66 Cramer DW, Sluss PM, Powers RD, McShane P, Ginsburgs ES, Hornstein MD, et al. Serum prolactin and TSH in an in vitro fertilization population: is there a link between fertilization and thyroid function? J Assist Reprod Genet. 2003 Jun;20(6):210-5.

67 Monteleone P, Parrini D, Faviana P, Carletti E, Casarosa E, Uccelli A, et al. Female infertility related to thyroid autoimmunity: the ovarian follicle hypothesis. Am J Reprod Immunol. 2011 Aug;66(2):108-14.

68 Lee YL, Ng HP, Lau KS, Liu WM, O WS, Yeung WS, et al. Increased fetal abortion rate in autoimmune thyroid disease is related to circulating TPO autoantibodies in an autoimmune thyroiditis animal model. Fertil Steril. 2009 May;91(5 Suppl):2104-9.

69 Zhong YP, Ying Y, Wu HT, Zhou CQ, Xu YW, Wang Q, et al. Relationship between antithyroid antibody and pregnancy outcome following in vitro fertilization and embryo transfer. Int J Med Sci. 2012;9(2):121-5.

70 Andrisani A, Sabbadin C, Marin L, Ragazzi E, Dessole F, Armanini D, et al. The influence of thyroid autoimmunity on embryo quality in women undergoing assisted reproductive technology. Gynecol Endocrinol. 2018 Sep; 34(9):752-5.

71 Ashkar FA, Semple E, Schmidt CH, St John E, Bartlewski PM, King WA. Thyroid hormone supplementation improves bovine embryo development in vitro. Hum Reprod. 2010 Feb; 25(2):334-44.

72 Rao M, Zeng Z, Zhou F, Wang H, Liu J, Wang $\mathrm{R}$, et al. Effect of levothyroxine supplementation on pregnancy loss and preterm birth in women with subclinical hypothyroidism and thyroid autoimmunity: a systematic review and meta-analysis. Hum Reprod Update. 2019 May;25(3):344-61.

73 Gallos ID, Eapen A, Price MJ, Sunkara SK, Macklon NS, Bhattacharya S, et al. Controlled ovarian stimulation protocols for assisted reproduction: a network meta-analysis. Cochrane Database Syst Rev. 2017;(3):CD012586

74 Poppe K, Glinoer D, Tournaye H, Schiettecatte J, Devroey P, van Steirteghem A, et al. Impact of ovarian hyperstimulation on thyroid function in women with and without thyroid autoimmunity. J Clin Endocrinol Metab. 2004 Aug;89(8):3808-12. 
75 Ain KB, Mori Y, Refetoff S. Reduced clearance rate of thyroxine-binding globulin (TBG) with increased sialylation: a mechanism for estrogen-induced elevation of serum TBG concentration. J Clin Endocrinol Metab. 1987 Oct;65(4):689-96.

76 Mintziori G, Goulis DG, Toulis KA, Venetis CA, Kolibianakis EM, Tarlatzis BC. Thyroid function during ovarian stimulation: a systematic review. Fertil Steril. 2011 Sep;96(3): $780-5$.

77 Muller AF, Verhoeff A, Mantel MJ, De Jong $\mathrm{FH}$, Berghout A. Decrease of free thyroxine levels after controlled ovarian hyperstimulation. J Clin Endocrinol Metab. 2000 Feb; 85(2):545-8.

78 Poppe K, Glinoer D, Tournaye H, Schiettecatte J, Haentjens P, Velkeniers B. Thyroid function after assisted reproductive technology in women free of thyroid disease. Fertil Steril. 2005 Jun;83(6):1753-7.

79 Gracia CR, Morse CB, Chan G, Schilling S, Prewitt M, Sammel MD, et al. Thyroid function during controlled ovarian hyperstimulation as part of in vitro fertilization. Fertil Steril. 2012 Mar;97(3):585-91.

80 Reinblatt S, Herrero B, Correa JA, ShalomPaz E, Ata B, Wiser A, et al. Thyroid stimulating hormone levels rise after assisted reproductive technology. J Assist Reprod Genet. 2013 Oct;30(10):1347-52.

81 Benaglia L, Busnelli A, Somigliana E, Leonardi M, Vannucchi G, De Leo S, et al. Incidence of elevation of serum thyroid-stimulating hormone during controlled ovarian hyperstimulation for in vitro fertilization. Eur $\mathrm{J}$ Obstet Gynecol Reprod Biol. 2014 Feb;173: 53-7.

82 Busnelli A, Somigliana E, Benaglia L, Sarais V, Ragni G, Fedele L. Thyroid axis dysregulation during in vitro fertilization in hypothyroidtreated patients. Thyroid. 2014 Nov;24(11): $1650-5$.
83 Abdul Karim AK, Azrai Abu M, Chelliah B, Mohd Razi ZR, Omar MH, Othman H, et al. Maternal thyroid function in women undergoing controlled ovarian hyperstimulation during in-vitro fertilization and its relation to reproductive outcome. Minerva Ginecol. 2017 Oct; 69(5):431-7.

84 Poppe K, Unuane D, D'Haeseleer M, Tournaye $\mathrm{H}$, Schiettecatte J, Haentjens $\mathrm{P}$, et al. Thyroid function after controlled ovarian hyperstimulation in women with and without the hyperstimulation syndrome. Fertil Steril. 2011 Jul;96(1):241-5.

85 Poppe K, Glinoer D, Tournaye H, Devroey P, Velkeniers B. Impact of the ovarian hyperstimulation syndrome on thyroid function. Thyroid. 2008 Jul;18(7):801-2.

86 Noppen M, Velkeniers B, Buydens P, Devroey P, Van Steirteghem A, Vanhaelst L. Hyperthyroidism after gonadotrophic ovarian stimulation. Br Med J. 1988 Jan;296(6616):171-2.

87 Korevaar TI, Steegers EA, Pop VJ, Broeren MA, Chaker L, de Rijke YB, et al. Thyroid autoimmunity impairs the thyroidal response to human chorionic gonadotropin: two population-based prospective cohort studies. J Clin Endocrinol Metab. 2017 Jan;102(1):69-77.

88 Akhtar MA, Agrawal R, Brown J, Sajjad Y, Craciunas L. Thyroxine replacement for subfertile women with euthyroid autoimmune thyroid disease or subclinical hypothyroidism. Cochrane Database Syst Rev. 2019 Jun; 6(6):CD011009.

89 Negro R, Mangieri T, Coppola L, Presicce G, Casavola EC, Gismondi R, et al. Levothyroxine treatment in thyroid peroxidase antibodypositive women undergoing assisted reproduction technologies: a prospective study. Hum Reprod. 2005 Jun;20(6):1529-33.
90 Reh A, Grifo J, Danoff A. What is a normal thyroid-stimulating hormone (TSH) level? Effects of stricter TSH thresholds on pregnancy outcomes after in vitro fertilization. Fertil Steril. 2010 Dec;94(7):2920-2.

91 Fumarola A, Grani G, Romanzi D, Del Sordo M, Bianchini M, Aragona A, et al. Thyroid function in infertile patients undergoing assisted reproduction. Am J Reprod Immunol. 2013 Oct;70(4):336-41.

92 Chai J, Yeung WY, Lee CY, Li HW, Ho PC, $\mathrm{Ng} \mathrm{HY}$. Live birth rates following in vitro fertilization in women with thyroid autoimmunity and/or subclinical hypothyroidism. Clin Endocrinol. 2014 Jan;80(1):122-7.

93 Karmon AE, Batsis M, Chavarro JE, Souter I. Preconceptional thyroid-stimulating hormone levels and outcomes of intrauterine insemination among euthyroid infertile women. Fertil Steril. 2015 Jan;103(1):258-63.e1.I

94 Wilson JM, Jungner G. Principles and practice of screening for disease. In: World Health Organization, ed. Public health papers, vol. 34. Geneva, Switzerland: World Health Organization; 2011.

95 Korevaar TIM, Medici M, Visser TJ, Peeters RP. Thyroid disease in pregnancy: new insights in diagnosis and clinical management. Nat Rev Endocrinol. 2017 Oct;13(10):610-22.

96 Practice Committee of the American Society for Reproductive Medicine. Subclinical hypothyroidism in the infertile female population: a guideline. Fertil Steril. 2015 Sep;104(3):545-53.

97 Bliddal S, Feldt-Rasmussen U, Rasmussen ÅK, Kolte AM, Hilsted LM, Christiansen OB, et al. Thyroid peroxidase antibodies and prospective live birth rate: a cohort study of women with recurrent pregnancy loss. Thyroid. 2019 Oct;29(10):1465-74. 